\title{
Predictors of serious complications associated with lower gastrointestinal endoscopy in a major city-wide health region
}

\author{
Harminder Singh MD MPH ${ }^{1,2}$, Robert B Penfold $\mathrm{PhD}^{3,4}$, Carolyn De Coster PhD RN MBA ${ }^{2}$, \\ Wendy Au BSc${ }^{2}$, Charles N Bernstein MD ${ }^{1}$, Michael Moffatt MSc MD²,3
}

H Singh, RB Penfold, C De Coster, W Au, CN Bernstein, M Moffatt. Predictors of serious complications associated with lower gastrointestinal endoscopy in a major city-wide health region. Can J Gastroenterol 2010;24(7):425-430.

BACKGROUND: There are limited data regarding complications associated with colonoscopy and flexible sigmoidoscopy in usual clinical practice in Canada.

OBJECTIVE: To determine the risk factors for lower gastrointestinal (GI) endoscopy-associated complications in usual clinical practice.

METHODS: All outpatient lower GI endoscopies performed in Winnipeg (Manitoba) between April 1, 2004 and March 31, 2006, were identified from the provincial physicians' claims database. All subsequent hospital admissions within 30 days that documented potential complications associated with lower GI endoscopies were identified from the electronic hospital discharges database and reviewed. Multivariate generalized estimating equation regression analysis was performed to determine independent factors (patient, endoscopist and procedure) associated with the risk of developing complications.

RESULTS: There were 29,990 outpatient lower GI endoscopies performed in Winnipeg during the years studied. Seventy-seven $(0.26 \%)$ procedures were associated with complications requiring hospitalization within 30 days of the index procedure. Stricture dilation (rate ratio [RR] 23.14; $95 \%$ CI 6.70 to 76.51 ), polypectomy (RR 5.93; $95 \%$ CI 3.66 to 9.62), increasing patient age (for each year increase in age, RR 1.03 ; $95 \%$ CI 1.01 to 1.05 ) and performance of endoscopy by lowvolume endoscopists (fewer than 200 procedures per year, RR 2.28; 95\% CI 1.18 to 4.42 ) and family physicians (RR 2.23; 95\% CI 1.39 to $3.58)$ were independently associated with complications.

CONCLUSIONS: The results of the present study suggest that increasing patient age, complex procedures and performance of the index procedure by low-volume endoscopists are independent risk factors for lower GI endoscopy-associated complications in usual clinical practice. This suggests that it may be time to consider implementing minimum volume requirements for endoscopists performing nonscreening lower GI endoscopies.

Key Words: Colonoscopy; Endoscopy-associated complications; Flexible sigmoidoscopy

\section{Prédicteurs des complications graves associées à l'endoscopie GI basse dans la région sanitaire d'un grand centre urbain}

HISTORIQUE : On dispose de données limitées au sujet des complications de la colonoscopie et de la sigmoïdoscopie dans la pratique clinique habituelle au Canada.

OBJECTIF : Déterminer quels sont les facteurs de risque de complications associées aux endoscopies gastro-intestinales basses dans la pratique clinique habituelle.

MÉTHODE : Toutes les endoscopies GI basses effectuées en externe à Winnipeg (Manitoba) entre le $1^{\text {er }}$ avril 2004 et le 31 mars 2006 ont été recensées à partir d'une base de données provinciale sur la rétribution des médecins. Toutes les hospitalisations subséquentes dans les 30 jours qui faisaient état de complications potentiellement associées aux endoscopies GI basses ont été relevées à partir de la base de données électronique des congés hospitaliers et passées en revue. Une analyse de régression multivariée de l'équation d'estimation généralisée a été effectuée afin de déterminer les facteurs indépendants (patients, endoscopistes et interventions) associés au risque de complications.

RÉSULTATS : Vingt neuf mille neuf cent quatre-vingt-dix (29 990) endoscopies GI basses ont été réalisées en externe à Winnipeg durant les années étudiées. Soixante-dix-sept (0,26\%) interventions ont été associées à des complications nécessitant une hospitalisation dans les 30 jours de l'intervention initiale. La dilatation de strictures (risque relatif [RR] 23,14; IC à $95 \%, 6,70$ à 76,51), la polypectomie RR 5,93, IC à 95\%, 3,66 à 9,62), l'avancée en âge des patients (pour chaque année supplémentaire, RR 1,03, IC à $95 \%, 1,01$ à 1,05) et l'exécution de l'endoscopie par des endoscopistes ayant un volume moins élevé (moins de 200 interventions par année) (RR 2,28, IC à $95 \%, 1,18$ à 4,42) et des médecins de famille (RR 2,23, IC à $95 \%, 1,39$ à 3,58) étaient liées de façon indépendante aux les complications.

CONCLUSIONS : Les résultats de la présente étude donnent à penser que l'avancée en âge des patients, la complexité des interventions et le rendement des interventions initiales pratiquées par des endoscopistes ayant un moins fort volume constituent des facteurs de risque indépendants de complications liées à l'endoscopie GI basse dans la pratique clinique habituelle. On en déduit qu'il est peut-être temps d'envisager l'application de critères minimum en termes de volume pour les endoscopistes qui procèdent à des endoscopies GI basses ne servant pas au dépistage.
$\mathrm{T}$ The use of colonoscopy is increasing rapidly (1) and is likely related to the increased recognition of the mortality and morbidity associated with colorectal cancer, and increased screening for colorectal cancer. However, until recently, there were no population-based estimates of complications associated with lower gastrointestinal (GI) endoscopy, including colonoscopy performed in Canada. A recent four-province study (2) reported colonoscopy-related bleeding and perforation rates of 1.64 per 1000 procedures and 0.85 per 1000 procedures, respectively. This study did not evaluate the risk of other

${ }^{1}$ Section of Gastroenterology; ${ }^{2}$ Community Health Sciences, University of Manitoba; ${ }^{3}$ Winnipeg Regional Health Authority, Winnipeg, Manitoba;

${ }^{4}$ Department of Population Medicine, Harvard Medical School, Boston, Massachusetts, USA

Correspondence: Dr Harminder Singh, Section of Gastroenterology, University of Manitoba, 804-715 McDermot Avenue, Winnipeg,

Manitoba R3E 3P4. Telephone 204-480-1311, fax 204-789-3972, e-mail singh@cc.umanitoba.ca

Received for publication October 12, 2009. Accepted October 23, 2009 
life-threatening complications such as cardiovascular complications or complications associated with flexible sigmoidoscopy (FS). Moreover, by limiting the analyses to procedures coded as colonoscopy in the administrative databases, this study may have underestimated the risks associated with colonoscopy. When a colonoscopy is aborted due to a complication observed during the procedure, the procedure may be recorded as FS in a database and complications would, therefore, be incorrectly associated with FS (3). Such adverse events would not be regarded as being associated with colonoscopy when only procedures coded as colonoscopies are evaluated.

We recently reported (4) that the risk of complications associated with colonoscopy and FS performed as outpatient procedures in Winnipeg (Manitoba) hospitals was higher if the index procedure was performed by low-volume endoscopists. However, we were unable to adjust our previous analysis for potentially important factors such as patient comorbidities and procedure complexity. In addition, we did not have information regarding the procedures performed in the ambulatory care centres. We have now extended our analysis to include procedures performed in ambulatory care facilities and assessed the relationship among patient, procedure, physician characteristics and complications of lower GI endoscopy.

\section{METHODS}

\section{Data sources}

With a population of approximately 700,000 , Winnipeg is the largest city in Manitoba. From April 1, 2004 to March 31, 2006, approximately two-thirds of lower GI endoscopies in the province were performed in Winnipeg. In an earlier analysis (4), all adults (age older than 16 years) who had lower GI endoscopies performed as outpatient procedures at any one of the six hospitals in Winnipeg in which the majority of endoscopies are performed, were identified from the city-wide hospital discharges database. All hospitalizations within 30 days of the index procedure with discharge diagnoses that potentially indicated a complication associated with lower GI endoscopy were identified using an exhaustive list of International Classification of Diseases, 10th Revision, Canada codes. Using a careful and systematic chart review, all cases with complications were confirmed. The sensitivity of the selected discharge diagnosis codes was established by reviewing $20 \%$ of hospitalizations within 30 days of a lower GI endoscopy that did not have a selected diagnosis code. The results of this analysis revealed no additional cases of lower GI endoscopy-associated complications.

In the current study, an anonymized version of the previously collected data was linked to the population-based administrative data repository housed at the Manitoba Centre for Health Policy at the University of Manitoba (Winnipeg). The data repository includes all provincial physician billing claims as well as all hospital discharges. Since 1984, every resident of Manitoba has been assigned a unique personal health identification number (PHIN) by Manitoba Health and Healthy Living - the province's single health insurance provider. With the PHIN as a key identifier, longitudinal health service use and outcomes in the province can be determined by linkage of health files. For the present study, our previous study database was linked with the provincial physician claims and hospital discharges databases. All linkages were performed with encrypted PHINs to protect patient privacy.

\section{Identification of potential additional cases with complications}

All outpatient lower GI endoscopies (FSs and colonoscopies) performed in the city of Winnipeg were identified from the physician medical claims database using the tariff codes 3185 , 3186, 3187, 3189, 3320 and 3323 (5). Procedures performed on inpatients, which were identified from the hospital discharges database, and individuals younger than 16 years of age on the date of the index procedure, were excluded. All hospitals and almost all ambulatory care facilities (except two in Winnipeg and one in the city of Brandon) in the province have facility numbers, which are listed in the physician billing claim for lower GI endoscopy. The claims without facility numbers were considered to be performed at ambulatory care centres because all hospitals have a facility number. Procedures performed outside of Winnipeg were excluded based on physicians' primary practice areas, defined as the area where most of their patients lived.

Using the previously described list of 129 International Classification of Diseases, 10th Revision, Canada codes (4), 152 additional hospital admissions were identified for chart review to determine the occurrence of serious lower GI endoscopyassociated complications within 30 days of the index procedure. Similar to other studies $(2,6,7)$, serious complications were defined as those requiring an inpatient hospital admission. As in the previous analysis, acute myocardial infarction, renal failure, dehydration and intestinal obstruction were considered to be related to the index procedure if the onset of symptoms occurred within two days of the index procedure. Episodes of pneumonias and acute diverticulitis were attributed to the index procedure if the onset of symptoms occurred within four days of the index procedure.

\section{Determination of predictors of complications}

Patient characteristics (age, sex, socioeconomic status [SES], comorbidity level, history of inflammatory bowel disease, previous resective colorectal surgery), physician characteristics (specialty and volume of procedures performed), performance site of index procedure (hospital versus ambulatory care centres) and nature of the procedure (colonoscopy, sigmoidoscopy, polypectomy and stricture dilation) were evaluated for their association with complications of lower GI endoscopy.

Patient SES was assigned based on their neighbourhood of residence at the time of the index procedure. The 2001 dissemination area (the smallest geographical unit of the Canadian Census) average household income was used to proxy individuallevel income and group the dissemination areas into five population quintiles. Previous studies $(8,9)$ from the province have shown a strong correlation between self-reported household income and a person's neighbourhood average income. The SES can be a significant predictor of lower GI endoscopy use (10). The John Hopkins Aggregated Diagnosis Groups method (11) was used to stratify subjects into low, moderate or high morbidity categories. History of inflammatory bowel disease was determined from a previously validated administrative data definition (12), which relies on information from the physician claims and hospitalization databases. History of resective colorectal surgery before the index procedure was determined from the physicians' claims database. For the volume of procedures performed, the same categories as in the 
earlier analysis (fewer than 200, 200 to 300, and more than 300 procedures/year) were used; however, for the present study, the number of procedures performed in ambulatory care facilities was also included. Of note, there is no separate billing code in the province for sigmoidoscopy with biopsy and, therefore, it was not possible to compare risks after sigmoidoscopy that included biopsy with those of sigmoidoscopy that did not include biopsy.

\section{Statistical analysis}

SAS version 9.1 (SAS Institute Inc, USA) was used for data management and analyses. Marginal generalized estimating equation regression analysis was used to adjust for clustering of patients among the endoscopists. A zero-inflated Poisson model structure was tested to determine whether the data were overdispersed (ie, a lower than expected rate of complications may have been observed if many procedures were aborted). Ultimately, a Poisson model structure for multivariate analysis was used because the inflation probability with the null version of the zero-inflated Poisson model was not significant $(\mathrm{P}=0.99)$.

Based on the results of the univariate analysis, some categories of variables were combined to develop the most parsimonious final multivariate model. For example, because there was no difference between the risks after colonoscopy with and that without biopsy in the univariate analysis, colonoscopy with and without biopsy were considered together (referred to as CSPY from here on) in multivariate analyses. Similarly, the two highest procedure volume endoscopist categories were considered together in the multivariate analysis. The comparison of FS and CSPY was included a priori in the multivariate model. All other factors were retained in the multivariate model if they were significant at $\mathrm{P}<0.10$ in the univariate models. Almost all of the procedures performed at ambulatory care centres were performed by endoscopists who were in the top two volume categories (99.5\%) and by gastroenterologists (91\%); therefore, the procedure performance site was not considered in the multivariate analysis.

The present study was approved by the University of Manitoba's Health Research Ethics Board and the Health Information and Privacy Committee of Manitoba.

\section{RESULTS}

There were 29,990 outpatient lower GI endoscopies performed in adults (older than 16 years of age) in Winnipeg between April 1, 2004 and March 31, 2006. Of these, 4821 (17\%) were performed in ambulatory care centres. Gastroenterologists and general surgeons performed an approximately equal proportion (48\%) of the procedures, with family physicians performing $4 \%$. The median age of the individuals undergoing the procedures was 58 years (interquartile range 48 to 70 years), and $55 \%$ were women. Seventy-seven $(0.26 \%)$ procedures were associated with complications requiring hospitalization within 30 days of the index procedure (Table 1 ). The median age of the individuals who developed complications was 68 years (interquartile range 54 to 77 years). In addition to intestinal wall perforation and postpolypectomy bleeding, the most common complications were postpolypectomy syndrome, intestinal obstruction, acute diverticulitis and acute myocardial infarction (Table 1). Similar to other studies (6), postpolypectomy syndrome was defined as new-onset severe abdominal pain without evidence of frank perforation on imaging studies. The
TABLE 1

Nature of complications after 29,990 outpatient lower gastrointestinal endoscopies performed in Winnipeg, Manitoba, between April 1, 2004 and March 31, 2006*

\begin{tabular}{lcc}
\hline Complication & $\mathbf{n}$ & $\begin{array}{c}\text { Rate per } \mathbf{1 0 0 0} \\
\text { procedures } \\
(95 \% \mathbf{C l})\end{array}$ \\
\hline Perforations & 33 & $1.1(0.76-1.55)$ \\
Postpolypectomy bleeding & 22 & $0.73(0.46-1.11)$ \\
Postpolypectomy syndrome $^{\dagger}$ & 10 & $0.33(0.16-0.61)$ \\
Intestinal obstruction or acute & 5 & $0.17(0.05-0.39)$ \\
$\quad$ diverticulitis & & \\
Acute myocardial infarction & 4 & $0.13(0.04-0.34)$ \\
Other $^{\ddagger}$ & 6 & $2.63(2.09-3.28)$ \\
\hline
\end{tabular}

*Seventy-seven procedures were associated with 80 complications; ${ }^{\dagger}$ Postpolypectomy syndrome was defined (as in other studies) as new-onset severe abdominal pain without evidence of frank perforation on imaging studies; ${ }^{\ddagger}$ Other include bleeding after biopsy, hemoperitoneum, persistent vomiting, pneumonia and acute renal failure

majority $(n=40[52 \%])$ of the complications occurred following polypectomy. There was no difference in the rate of complications between polypectomies performed at sigmoidoscopy ( 8.4 of 1000 procedures) and those performed during colonoscopy (9.4 of 1000 procedures) $(\mathrm{P}=0.88)$.

\section{Predictors of complications}

In univariate analysis, increasing patient age, male sex, higher patient comorbidities, index procedure performed by family physicians, lowest volume endoscopists, polypectomy and stricture dilation were associated with complications at a significance level of $\mathrm{P}<0.10$ (Table 2). Therefore, these factors were included in the final multivariate model. In multivariate analysis, stricture dilation, polypectomy, increasing patient age and performance of endoscopy by the lowest volume endoscopists and family physicians were independently associated with a risk of complications (Table 3 ). There was a trend toward more complications among men $(\mathrm{P}=0.05)$. In a multivariate model restricted to procedures performed by surgeons and gastroenterologists (and including all other variables), there was no difference in the risk of complications between the procedures performed by surgeons or gastroenterologists $(\mathrm{P}=0.87)$.

\section{DISCUSSION}

In the present study, we found that increasing patient age, complex procedures (eg, polypectomy or stricture dilation) and performance of the index procedure by low-volume endoscopists were independent risk factors for lower GI endoscopyassociated complications. The current study extends our previous unadjusted analysis (4) that was limited to data from Winnipeg hospitals, in which we demonstrated an increased risk of complications when the index procedure was performed by low-volume endoscopists in the six city hospitals. In contrast to the previous report, the present study assessed patient factors that may be associated with lower GI endoscopy-related complications and reported adjusted/independent effect of patient, procedure and physician characteristics on the risk of lower GI endoscopy-associated complications.

Until recently, there were no estimates of complication rates associated with lower GI endoscopy in usual practice from Canada. The described rates of colonic wall perforations and 
TABLE 2

Predictors of lower gastrointestinal (GI) endoscopy-associated complications (univariate analyses)

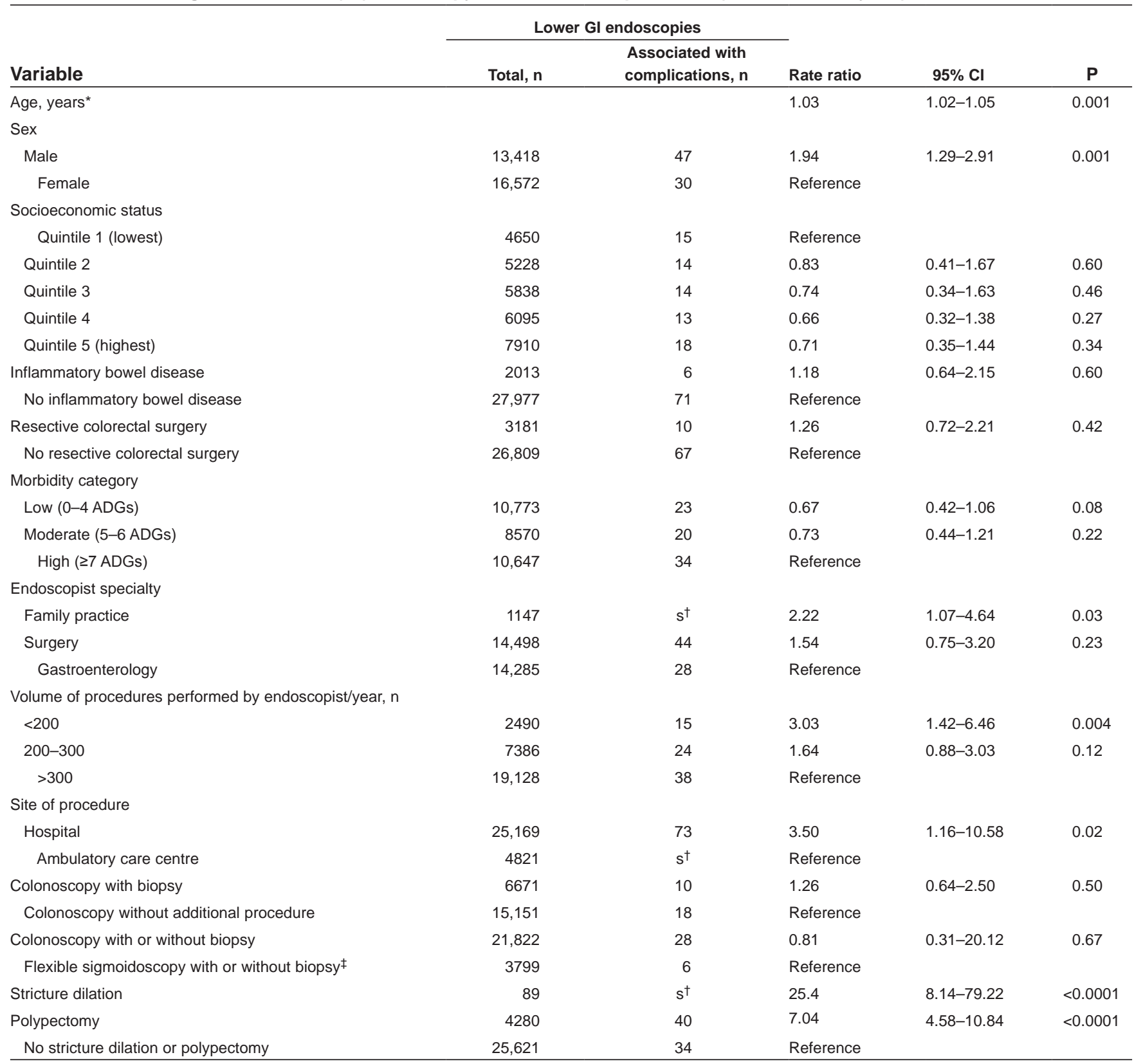

${ }^{*}$ Age was evaluated as a continuous variable; therefore, the rate ratio for age is for each year increase in age; ${ }^{\dagger}$ Suppressed counts due to small cell size (ie, $\left.n \leq 5\right)$;

${ }^{\ddagger}$ Tariff code for flexible sigmoidoscopy with biopsy is same as that for sigmoidoscopy without biopsy. ADGs Aggregated diagnostic groups

postpolypectomy bleeding are comparable with those reported in another recent Canadian study (2) and those in other studies (13). We also found that acute myocardial infarction, intestinal obstruction and acute diverticulitis were significant complications associated with lower GI endoscopy. This is in contrast to a recent United States (US) Medicare administrative database study (14) that did not find an increased risk of cardiovascular complications associated with colonoscopy compared with a control group of individuals who did not undergo colonoscopy. However, the US Medicare study evaluated cardiovascular events within 30 days, rather than in the immediate periprocedural time period of the index procedure. Most of the cardiac events directly related to a procedure occur within the first few days of the index procedure (15). More events later in the month, when there may be no difference between the colonoscopy and the control groups, could have masked any true difference in the rates of cardiovascular events in the first few days. Similar to the studies conducted by the Kaiser Permanente Medical Care Program in California (USA) $(6,7)$, we considered acute diverticulitis within a few days of the index procedure to be a complication associated with the index procedure as diverticulitis caused by a microscopic perforation of pre-existing diverticulosis in the colon.

Our study suggests that the higher rate of complications associated with procedures performed by low-volume endoscopists is independent of the complexity of the procedure and patient characteristics. Most other studies have been unable to examine endoscopist characteristics associated with lower GI 
endoscopy-related complications due to the similar characteristics of the endoscopists performing the procedures in those studies $(6,16)$. The other recent Canadian study also found an increased rate of complications with colonoscopy performed by low-volume endoscopists. This finding supports the decision in many jurisdictions (including Germany, Austria and the province of Ontario) to limit colonoscopies for colorectal cancer screening programs to higher-volume endoscopists $(17,18)$. Where feasible, perhaps it is time to also consider implementing volume requirements for endoscopists performing colonoscopies of any nature on an ongoing basis.

We found a linear increase in risks associated with increasing patient age. This finding was similar to that reported in the US Medicare study (14), and reinforces that the benefits and risks of lower GI endoscopy should be carefully weighed in the elderly before the procedures. Specific comorbidities and/or medication use could be mediating and/or contributing to the higher risk of complications in older individuals. The risk of complications in older individuals without comorbidities and/or medication use needs to be determined in future studies. We found a trend toward an increased complication rate in men; however, the reasons for this finding, which has been reported in other studies $(2,7)$, remain unclear.

Surprisingly, we found no difference in complication rates between FS and colonoscopy. The use of FS has markedly decreased over recent years (1), and it is likely that FS is now being performed in only highly selected cases. In addition, although we carefully reviewed all of the charts, we may not have been able to determine the intent of the procedures in all cases that documented complications; therefore, some of the FS-associated complications may have been cases in which the intended colonoscopy was stopped due to complications.

Our study findings should be interpreted in the context of study strengths and limitations. In contrast to other recent database studies, we reviewed all charts to confirm complications. We evaluated procedures coded as colonoscopies and sigmoidoscopies in the same study to capture aborted colonoscopies with complications that may have been coded as FSs in the databases. Indeed, we found a total of four such cases, in which the intent was colonoscopy, but the procedure was stopped due to a complication. These cases were recorded as FS in the database but were considered to have colonoscopyassociated complications in the present study. We evaluated a nonselected city-wide practice. However, although this was a large study, the number of events was relatively small, which resulted in imprecise estimates (ie, wide CIs) for particular subgroups such as specific complications. We included all lower GI endoscopies and, hence, our results may not directly apply to screening procedures. Similar to other administrative database studies (19), we could not determine the indications for the procedures. The risk of complications may vary according to the indication of the index procedure. For example, screening procedures are usually performed in healthy individuals and, therefore, may be associated with a lower risk of complications. We evaluated serious complications defined as those requiring admission to a hospital and did not assess complications that did not lead to hospitalization because the provincial databases do not regularly record diagnoses for emergency room visits that do not lead to hospitalization.
TABLE 3

Predictors for lower gastrointestinal endoscopy-associated complications (multivariate generalized estimating equation analysis)

\begin{tabular}{|c|c|c|c|}
\hline & Rate ratio & $95 \% \mathrm{Cl}$ & $\mathbf{P}$ \\
\hline Age, years* & 1.03 & $1.01-1.05$ & 0.01 \\
\hline \multicolumn{4}{|l|}{ Sex } \\
\hline Male & 1.55 & $1.0-2.41$ & 0.05 \\
\hline Female & Reference & & \\
\hline \multicolumn{4}{|l|}{ Morbidity category } \\
\hline Low (0-5 ADGs) & 1.18 & $0.75-1.86$ & 0.47 \\
\hline Moderate to high ( $\geq 6$ ADGs) & Reference & & \\
\hline \multicolumn{4}{|l|}{ Endoscopist specialty } \\
\hline Family practice & 2.23 & $1.39-3.58$ & $<0.001$ \\
\hline Surgery/gastroenterology & Reference & & \\
\hline \multicolumn{4}{|l|}{$\begin{array}{l}\text { Volume of procedures performed } \\
\text { by endoscopist, } n\end{array}$} \\
\hline$<200 /$ year & 2.28 & $1.18-4.42$ & 0.01 \\
\hline >200/year & Reference & & \\
\hline $\begin{array}{l}\text { Flexible sigmoidoscopy } \\
\text { with or without biopsy }\end{array}$ & 1.01 & $0.42-2.41$ & 0.98 \\
\hline $\begin{array}{l}\text { Colonoscopy with or } \\
\text { without biopsy }\end{array}$ & Reference & & \\
\hline Stricture dilation & 23.14 & $6.70-76.51$ & $<0.0001$ \\
\hline Polypectomy & 5.93 & $3.66-9.62$ & $<0.0001$ \\
\hline $\begin{array}{l}\text { No stricture dilation } \\
\text { or polypectomy }\end{array}$ & Reference & & \\
\hline
\end{tabular}

${ }^{*}$ Age was evaluated as a continuous variable; therefore, the rate ratio for age is for each year increase in age. ADGs Aggregated diagnostic groups

\section{CONCLUSION}

The results of the present study suggest that increasing patient age, lower GI endoscopy with polypectomy or stricture dilation, and performance of the index procedure by low-volume endoscopists and family physicians are independent risk factors for lower GI endoscopy-associated complications. The results of the current study, together with the results of the other recent Canadian study (2), suggest that all jurisdictions should carefully evaluate whether lower GI endoscopies should continue to be performed by low-volume endoscopists.

CONFLICTS OF INTEREST: None of the authors have conflicts of interest to declare. The results and conclusions are those of the authors, and no official endorsement by Manitoba Health and Healthy Living is intended or should be inferred.

FUNDING: Dr Singh is supported in part by the Dr FW Du Val Clinical Research Professorship Award. In the past year, he has served on the advisory board of Schering-Plough Canada. Dr Bernstein is supported in part by a Research Scientist Award of the Crohn's and Colitis Foundation of Canada and the Bingham Chair in Gastroenterology. In the past year, he has served on the advisory boards of Abbott Canada and Shire Canada, and has received research funding from UCB Canada.

\section{REFERENCES}

1. Singh H, Demers AA, Xue L, Turner D, Bernstein CN. Time trends in colon cancer incidence and distribution and lower gastrointestinal endoscopy utilization in Manitoba. Am J Gastroenterol 2008;103:1249-56.

2. Rabeneck L, Paszat LF, Hilsden RJ, et al. Bleeding and perforation after outpatient colonoscopy and their risk factors in usual clinical practice. Gastroenterology 2008;135:1899-906,1906. 
3. Schoen RE, Levin TR. Re: Risk of perforation after colonoscopy and sigmoidoscopy: A population-based study. J Natl Cancer Inst 2003;95:830-1.

4. Singh H, Penfold RB, DeCoster C, et al. Colonoscopy and its complications across a Canadian regional health authority. Gastrointest Endosc 2009;69(3 Suppl):665-71.

5. Government of Manitoba. Manitoba Physician's Manual. <http://www.gov.mb.ca/health/documents/physmanual.pdf > (Accessed on May 31, 2010).

6. Levin TR, Wei Z, Conell C, et al. Complications of colonoscopy in an integrated health care delivery system. Ann Intern Med 2006;145:880-6.

7. Levin TR, Conell C, Shapiro JA, Chazan SG, Nadel MR, Selby JV. Complications of screening flexible sigmoidoscopy. Gastroenterology 2002;123:1786-92.

8. Roos LL, Walld R, Uhanova J, Bond R. Physician visits, hospitalizations, and socioeconomic status: Ambulatory care sensitive conditions in a Canadian setting. Health Serv Res 2005:40:1167-85.

9. Mustard CA, Derksen S, Berthelot JM, Wolfson M. Assessing ecologic proxies for household income: A comparison of household and neighbourhood level income measures in the study of population health status. Health Place 1999;5:157-71.

10. Singh SM, Paszat LF, Li C, He J, Vinden C, Rabeneck L. Association of socioeconomic status and receipt of colorectal cancer investigations: A population-based retrospective cohort study. CMAJ 2004;171:461-5.
11. Reid RJ, Roos NP, MacWilliam L, Frohlich N, Black C. Assessing population health care need using a claims-based ACG morbidity measure: A validation analysis in the province of Manitoba. Health Serv Res 2002;37:1345-64.

12. Bernstein CN, Blanchard JF, Rawsthorne P, Wajda A. Epidemiology of Crohn's disease and ulcerative colitis in a central Canadian province: A population-based study. Am J Epidemiol 1999;149:916-24.

13. Lieberman DA. Clinical practice. Screening for colorectal cancer. N Engl J Med 2009;361:1179-87.

14. Warren JL, Klabunde CN, Mariotto AB, et al. Adverse events after outpatient colonoscopy in the Medicare population. Ann Intern Med 2009;150:849-57.

15. Gandhi R, Petruccelli D, Devereaux PJ, Adili A, Hubmann M, de Beer J. Incidence and timing of myocardial infarction after total joint arthroplasty. J Arthroplasty 2006;21:874-7.

16. Paspatis GA, Vardas E, Theodoropoulou A, et al. Complications of colonoscopy in a large public county hospital in Greece. A 10-year study. Dig Liver Dis 2008;40:951-7.

17. Rabeneck L, Rumble RB, Axler J, et al. Cancer Care Ontario Colonoscopy Standards: Standards and evidentiary base. Can J Gastroenterol 2007;21(Suppl D):5D-24D.

18. Pox C, Schmiegel W, Classen M. Current status of screening colonoscopy in Europe and in the United States. Endoscopy 2007;39:168-73.

19. Schenck AP, Klabunde CN, Warren JL, et al. Data sources for measuring colorectal endoscopy use among Medicare enrollees. Cancer Epidemiol Biomarkers Prev 2007;16:2118-27. 


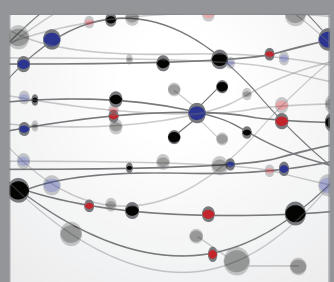

The Scientific World Journal
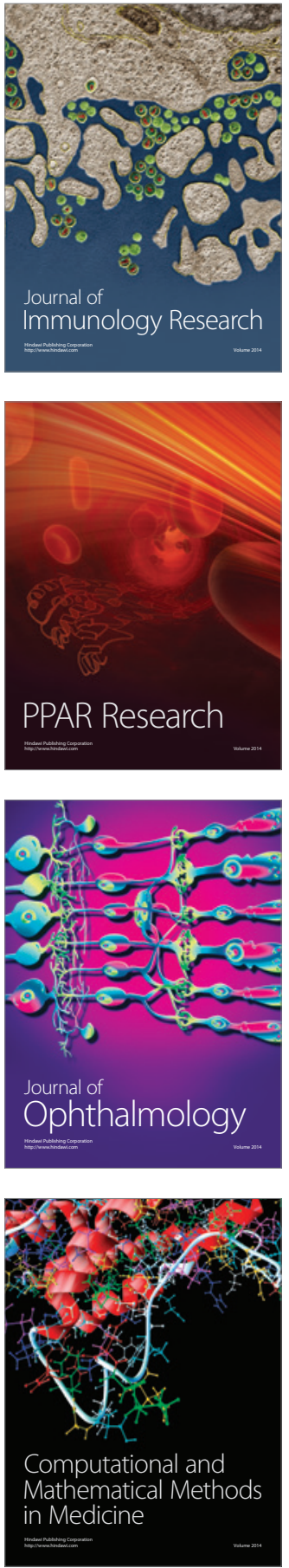

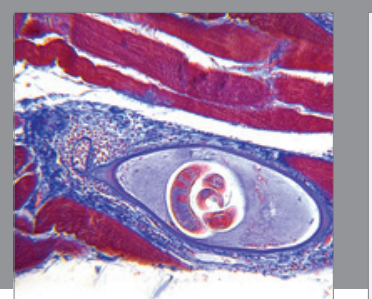

Gastroenterology Research and Practice

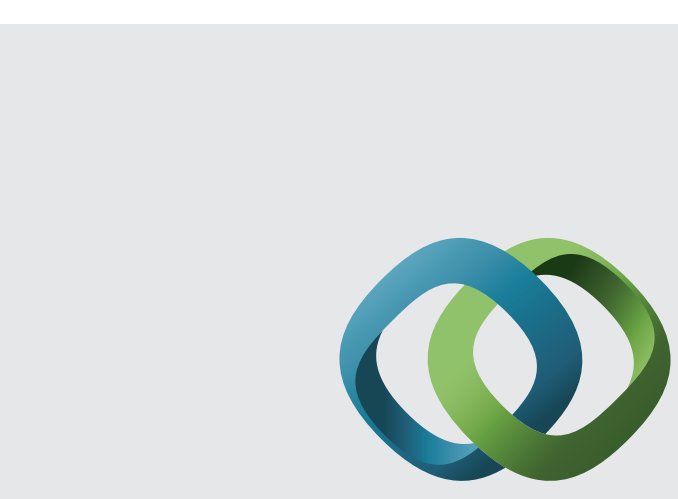

\section{Hindawi}

Submit your manuscripts at

http://www.hindawi.com
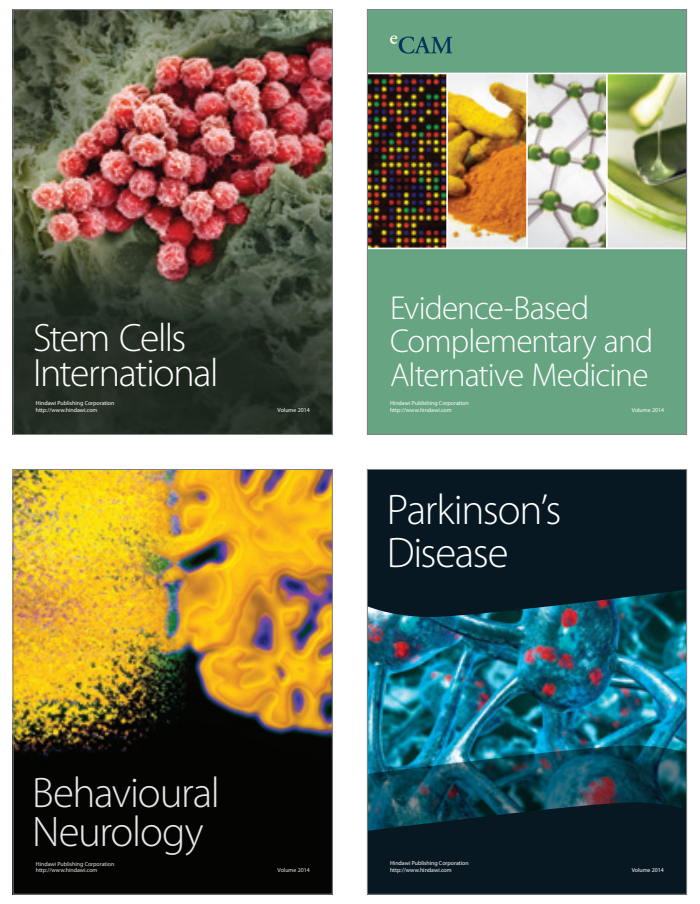
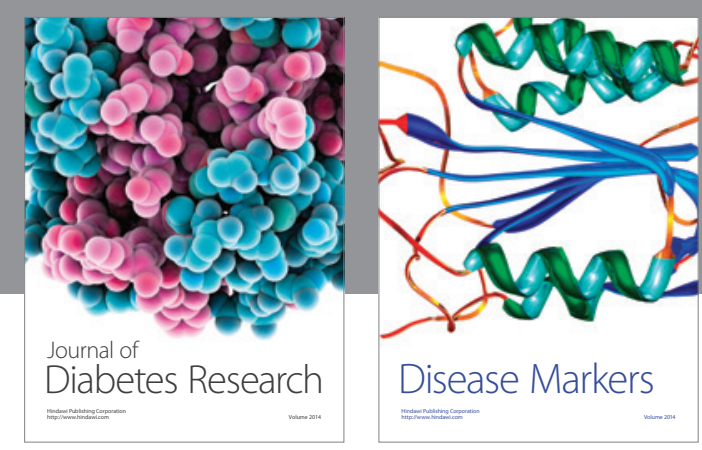

Disease Markers
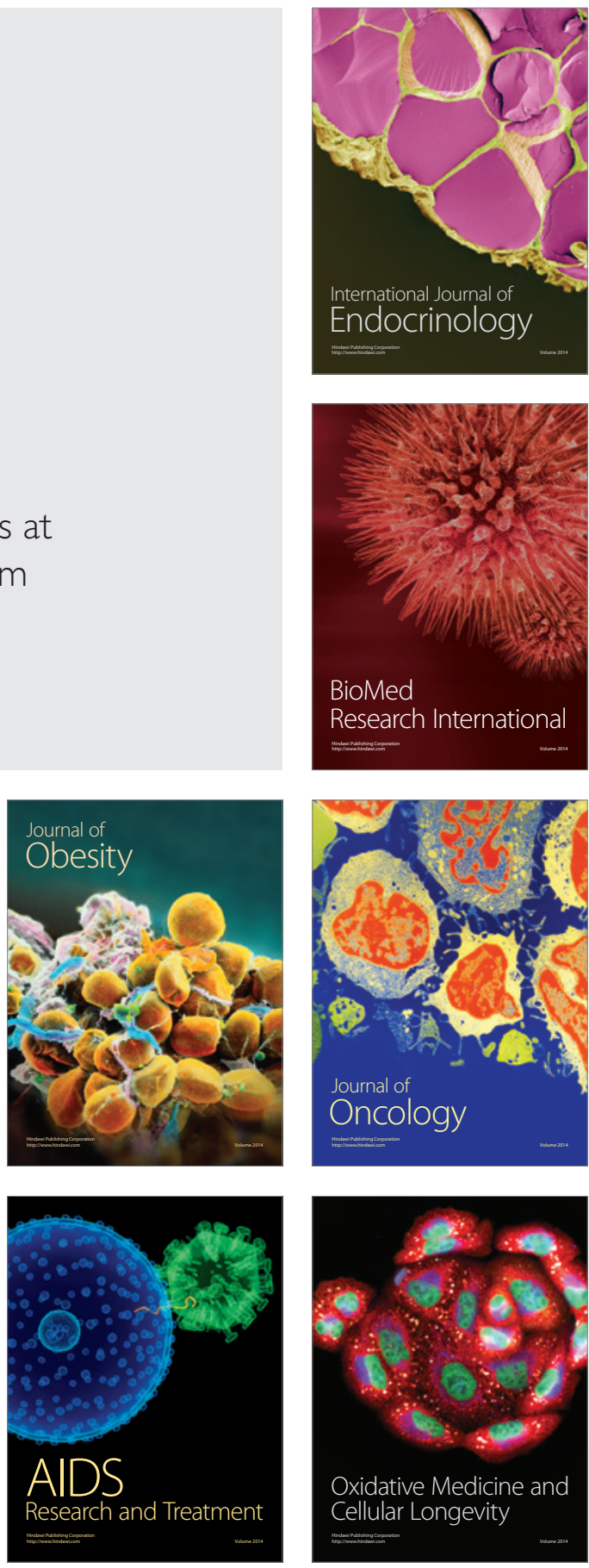